\title{
Deep sedation using propofol target- controlled infusion for gastrointestinal endoscopic procedures: a retrospective cohort study
}

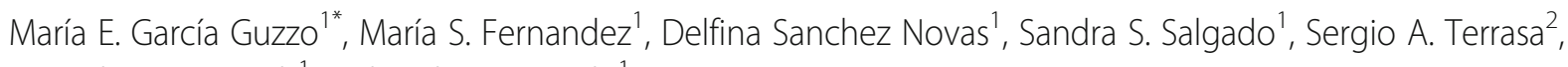
Gonzalo Domenech ${ }^{1}$ and Carlos A. Teijido ${ }^{1}$

\begin{abstract}
Background: Propofol sedation is effective for gastrointestinal endoscopic procedures, but its narrow therapeutic window highlights the importance of identifying an optimal administration technique regarding effectiveness and safety. This study aimed to determine the incidence of significant adverse events in adult patients scheduled for gastrointestinal endoscopy under anaesthetist-performed sedation using propofol target-controlled infusion and determine the existence of associations between these events and potentially related variables.
\end{abstract}

Methods: This single-centre, retrospective cohort study took place in a tertiary referral university hospital. Medical records of 823 patients (age > 18 years, American Society of Anesthesiologists physical status classification scores I-III) who had undergone elective gastrointestinal endoscopy under propofol target-controlled infusion sedation during September 2018 were reviewed. Outcomes included hypoxia, hypotension, and bradycardia events, requirement of vasoactive drugs, unplanned tracheal intubation or supraglottic device insertion, and need for advanced cardiac life support.

(Continued on next page)

\footnotetext{
* Correspondence: mariae.garcia@hospitalitaliano.org.ar

Outcomes from this work have been presented as an e-poster at the 2019

European Anesthesiology Congress of the European Society of

Anesthesiology (ESA) in Vienna, Austria, June 1 to June 3, 2019.

'Department of Anesthesiology, Hospital Italiano de Buenos Aires, Ciudad

Autónoma de Buenos Aires, Presidente Teniente General Juan Domingo

Perón 4190, 1199 Buenos Aires, Argentina

Full list of author information is available at the end of the article
}

C C The Author(s). 2020 Open Access This article is licensed under a Creative Commons Attribution 4.0 International License, which permits use, sharing, adaptation, distribution and reproduction in any medium or format, as long as you give appropriate credit to the original author(s) and the source, provide a link to the Creative Commons licence, and indicate if changes were made. The images or other third party material in this article are included in the article's Creative Commons licence, unless indicated otherwise in a credit line to the material. If material is not included in the article's Creative Commons licence and your intended use is not permitted by statutory regulation or exceeds the permitted use, you will need to obtain permission directly from the copyright holder. To view a copy of this licence, visit http://creativecommons.org/licenses/by/4.0/. The Creative Commons Public Domain Dedication waiver (http://creativecommons.org/publicdomain/zero/1.0/) applies to the data made available in this article, unless otherwise stated in a credit line to the data. 


\begin{abstract}
(Continued from previous page)
Results: The most frequently encountered adverse event was oxygen desaturation $<95 \%$ with an incidence of $22.35 \%$. Vasoactive drug administration, hypotension, and oxygen desaturation $<90 \%$ followed, with incidences of $19.2,12.64$, and $9.92 \%$, respectively. Only $0.5 \%$ of patients required advanced airway management. Multivariate analysis revealed an association between hypotension events, colonoscopic procedures, and propofol doses (odds ratio: $3.08,95 \%$ confidence interval: 1.43 to $6.61 ; P=0.004$ and odds ratio: $1.14,95 \%$ confidence interval: 1.00 to 1.29 ; $P=0.046$ ). A strong dose-effect relationship was found between hypoxia and obesity; patients with body mass index $\geq 40$ were nine times (odds ratio: 10.22, 95\% confidence interval: 2.83 to 36.99) more likely to experience oxygen desaturation $<90 \%$ events.

Conclusions: Propofol sedation using target-controlled infusion appears to be a safe and effective anaesthetic technique for gastrointestinal endoscopic procedures with acceptable rates of adverse events and could be more widely adopted in clinical practice.
\end{abstract}

Keywords: Propofol, Anaesthesiologists, Endoscopy, Gastrointestinal, Anaesthesia, intravenous, Deep sedation

\section{Background}

Presently, gastrointestinal endoscopic procedures (GIEPs) are mostly performed under sedation. In a few patients, general anaesthesia remains necessary due to procedure invasiveness or patient characteristics [1, 2]. Benzodiazepines combined with opioids, usually referred to as traditional sedative agents, are widely used for sedation by anaesthesia care providers and gastroenterologists in the US and elsewhere [3]. However, randomised studies have evaluated pharmacological alternatives for procedural sedation and have shown that propofol (Baxter International Inc., Deerfield, IL), compared with the use of traditional agents, has a rapid onset of action, provides predictable sedation depth and recovery times, and improves patient satisfaction rates [4-6]. Nonetheless, and despite its beneficial pharmacokinetic profile, propofol has a narrow therapeutic window and no antidote, highlighting the fact that it should be administered by certified health professionals using precise administration techniques to avoid critical events [7].

Worldwide, the safety profiles of different models of propofol administration have been analysed, such as nurse- and gastroenterologist-performed sedation, patient-controlled and computer-assisted methods, and anaesthetist-managed propofol sedation using intermittent boluses [8-10]. Among the studied models, propofol administration using target-controlled infusion (TCI) systems is emerging as an attractive alternative for anaesthetist-managed sedation. The current propofol TCI systems are pre-programmed with the Marsh and Schnider pharmacokinetic models. The rate constants in the Marsh model are fixed, whereas compartment volumes and clearances are weight proportionally; the Schnider model has several fixed values, whereas others are adjusted according to total weight, lean body mass, and height. One major benefit of the Schnider model is that it adjusts the doses and infusion rates according to patient age [11]. Through the use of microprocessor- controlled infusion pumps, the infusion rate is dynamically titrated to achieve plasmatic or effect site 'targeted' concentrations [12]. Over the past 5 years at our institution most gastrointestinal endoscopies have been performed under propofol TCI sedation administered by anaesthetists. Although this technique has proven to be effective, few investigations have reported the incidence of unplanned cardiovascular and respiratory adverse events during anaesthetist-managed propofol TCI sedation for GIEPs [13]. Therefore, sufficient evidence for improved safety over other anaesthetic strategies is lacking.

The primary aim of this historical cohort study was to describe the incidence of significant adverse events (cardiovascular and respiratory) in adult patients scheduled for elective outpatient GIEPs under anaesthetistperformed propofol TCI sedation and nasal cannula oxygenation. The secondary aim was to investigate associations between hypotension and oxygen desaturation events and potentially related variables (procedure type and duration, opioid administration, and total propofol dose among others) through multivariate analysis.

\section{Methods}

We conducted a single-centre retrospective cohort study in a tertiary referral university hospital. Electronic medical records of 823 adult patients were reviewed based on sample-size calculation. The included patients were $\geq 18$ years old, had American Society of Anesthesiologists (ASA) physical status classification scores I-III, and underwent elective outpatient GIEPs managed by anaesthetists using propofol TCI sedation during September 2018. According to the recommendations of the Anesthesiology Department, all gastrointestinal endoscopies are performed using TCI propofol sedation, with the exception of patients requiering general anesthesia due to individual or procedural characteristics or presenting contraindications to propofol administration. Patients 
scheduled for endoscopic retrograde cholangiopancreatography, enteroscopy, and procedures performed under planned tracheal intubation were excluded from the study.

Ethical approval was provided by the Ethics Committee of the Hospital Italiano de Buenos Aires, Buenos Aires, Argentina (Chairperson: Dr. Augusto Pérez, Ethical Committee $\mathrm{N}^{\circ}$ 3885) on September 24, 2018. The requirement for written informed consent was waived due to the retrospective nature of the study.

The patient variables recorded included sex, age, ASA physical status classification score, weight, height, and significant comorbidities (diabetes mellitus, arterial hypertension, dyslipidaemia, current/former tobacco smoking, coronary artery, cerebrovascular, and peripheral vascular diseases; congestive heart failure, chronic obstructive pulmonary disease, and obstructive sleep apnea). The procedures comprised diagnostic and therapeutic esophagogastroduodenoscopy (EGD), colonoscopy, or both. Procedure-related data recorded included anaesthetic strategy (propofol TCI sedation), total propofol dose (mg), use of opioid drugs (fentanyl), and total fentanyl dose (mcg); type of procedure (EGD, colonoscopy, or combined procedure), and procedure duration (minutes; including time for monitoring and nasal cannula placement, operating room (OR) checklist, and the procedure itself). Intra-procedural adverse events recorded were oxygen saturation $\left(\mathrm{SaO}_{2}\right)<90$ and $<95 \%$, arterial hypotension (systolic blood pressure $<90$ $\mathrm{mmHg}$ ), vasoactive drug administration, significant bradycardia (heart rate $<50$ beats/minute or chronotropic drug requirement), unplanned supraglottic device (SGD) insertion or endotracheal intubation, and need for advanced cardiac life support (ACLS). Postprocedural data recorded consisted of oxygen saturation $<90$ and $<95 \%$ events, arterial hypotension, nausea and/ or vomiting episodes or administration of antiemetic drugs, time to post anaesthetic care unit (PACU) discharge (minutes), unplanned post procedural hospitalisation, and need for ACLS.

The main data sources comprised electronic medical records, including procedure subsections with attached anaesthetic and post-anaesthetic charts (PDF documents). Anaesthetic charts are automatically generated during procedures by electronic capture of real-time vital-sign measurements from multiparameter monitors and graphically displayed. Drug administration and comments on adverse events are manually entered by anaesthesiologists. Upon case completion, a PDF document is generated and available for review in the procedure subsection. During the postprocedure period at the PACU, vital-sign measurements and drug administration are entered by PACU nurses, and a post-anaesthetic chart is generated upon discharge.
All patients scheduled for colonoscopy received bowel cleansing preparation (Pico-Sulphate - Picoprep or Polyethylene glycol - Barex ${ }^{\odot}$ Barex $\mathrm{Kit}^{\circ}$ ) before the procedure according to standardised hospital protocols. Vital signs were monitored (pulse oximeter, noninvasive blood pressure cuff, and five lead electrocardiography) once inside the operating room and after intravenous cannulation. Supplementary oxygen was delivered through a nasal cannula, and propofol was administered using TCI systems at titrated doses aiming for a deep level of sedation [14]. The TCI system included a Perfusor ${ }^{\circ}$ Space pump (B. Braun Melsungen AG, Melsungen, Germany) controlled by a microprocessor system. After introducing patient data, the Schnider or Marsh pharmacokinetic models and initial target concentrations were selected by the anaesthesiologist. Throughout the procedures, automatic adjustments to the infusion rate were generated by perfusor pumps based on the predicted plasma or tissue levels of propofol and the target concentrations set by the operator, guided by clinical judgement.

All patients were transferred to the PACU immediately after completion of the procedure and were monitored for at least $30 \mathrm{~min}$ before discharge.

Our primary outcome was the incidence of adverse cardiovascular and/or respiratory events among patients undergoing GIEP under propofol TCI sedation. The secondary outcome was the existence of associations between hypotension and oxygen desaturation events and potentially related variables.

\section{Sample size calculation}

Regarding the primary aim, we calculated a sample size of 823 patients based on an estimated incidence of $14 \%$ for $\mathrm{SaO}_{2}<95 \%$ events and aiming for a $\mathrm{CI}$ with a hemi amplitude of $2.5 \%$ [13]. An incidence of $5 \%$ was estimated for $\mathrm{SaO}_{2}<90 \%$ events in this population, predicting approximately 41 of these events among 823 patients. This allowed to build a multivariate model through the logistic regression technique including approximately four potentially related variables.

\section{Statistical analysis}

Descriptive analyses were performed using the mean \pm SD for continuous variables and numbers (proportions) for categorical variables. Qualitative variables derived from each group were compared using the $x^{2}$ test or Fisher's exact test in cases involving low expected counts. Student's t-test was used to analyse normally distributed quantitative data, while the nonparametric Wilcoxon rank-sum test was used to analyse non-normally distributed quantitative data. All statistical analyses were conducted using STATA.13 (StataCorp, College Station, TX). 
We conducted two multivariate logistic regression analyses to investigate which variables would be associated with the development of $\mathrm{SaO}_{2}<90 \%$ and hypotension events during propofol TCI sedation for GIEPs. For both models, variables were included based on significant associations $(P<0.1)$ with the event in the bivariate analysis. The final multivariate model for $\mathrm{SaO}_{2}<90 \%$ included age, ASA physical status classification score, obesity, EGD procedure, propofol doses, and fentanyl administration; for hypotension events the model included age, ASA physical status classification score, history of arterial hypertension, obesity, colonoscopic procedures, propofol doses, and fentanyl administration.

Finally, we performed linear regression to examine whether propofol doses would decrease when administered together with fentanyl, adjusting for potentially confounding factors such as age, ASA classification status, and body mass index (BMI).

\section{Results}

Medical records of 823 patients who underwent elective outpatient GIEPs under propofol TCI sedation were reviewed. Patients were aged $59.2 \pm 14.1$ years, $85 \%$ had ASA physical status classification scores I-II, and the mean BMI was $27.5 \pm 4.8$. The most frequently detected comorbidities were arterial hypertension (40.5\%) and dyslipidaemia (34.5\%) (Table 1).

The most commonly performed procedure was colonoscopy alone $(48.36 \%)$, followed by combined (EGD and colonoscopy) procedures (37.47\%) (Table 2). The mean propofol dose was $291.2 \pm 124.6 \mathrm{mg}$. Fentanyl was administered by $86.88 \%$ of anaesthetists combined with

Table 1 Baseline characteristics

\begin{tabular}{ll}
\hline & $\mathrm{TCl} \boldsymbol{n}=823$ \\
\hline Age, (years) & $59.2 \pm 14.1$ \\
Sex, (male) & $352(42.8 \%)$ \\
Weight. kg & $74.6 \pm 15.8$ \\
BMI (kg m ${ }^{2-1}$ ) & $27.5 \pm 4.8$ \\
ASA physical status, $\mathrm{n}(\%)$ & \\
$\quad$ I & $130(15.8 \%)$ \\
$\quad$ II & $567(68.9 \%)$ \\
$\quad$ III & $126(15.3 \%)$ \\
Diabetes, $\mathrm{n}(\%)$ & $70(8.5 \%)$ \\
Dyslipidaemia, $\mathrm{n}(\%)$ & $280(34.5 \%)$ \\
Hypertension, $\mathrm{n}$ (\%) & $333(40.5 \%)$ \\
Tobacco smoking, $\mathrm{n}(\%)$ & $119(14.5 \%)$ \\
Coronary artery disease, $\mathrm{n}(\%)$ & $23(2.8 \%)$ \\
Previous cerebrovascular disease, $\mathrm{n}(\%)$ & $12(1.5 \%)$ \\
\hline
\end{tabular}

Results are presented as mean \pm SD and number (proportion) $B M I$ body mass index, ASA American Society of Anesthesiologists propofol at a mean dose of $0.77 \pm 0.25 \mathrm{mcg} \mathrm{kg}^{-1}$. The global mean procedure duration was $25.07 \pm 11.43 \mathrm{~min}$ (Table 2).

The most frequently encountered adverse event was $\mathrm{SaO}_{2}<95 \%$, with an incidence of $22.36 \%(184 / 823)$. Vasoactive drug administration and arterial hypotension followed, with incidences of 19.2\% (158/823) and 12.64\% (104/823), respectively. The incidence of $\mathrm{SaO}_{2}<90 \%$ was 6.92\% (57/823), while the incidence of bradycardia or chronotropic drug requirement was 4.73\% (39/823). Only $0.5 \%$ of patients $(4 / 823)$ required advanced airway management (unplanned SGD insertion or orotracheal intubation). No patients required ACLS or died during the procedure (Table 3 ). All patients were transferred to the PACU immediately after completion of the procedure and received home discharge at a mean postprocedure time of $43.1 \pm 12.5 \mathrm{~min}$.

During the post-anaesthetic period, the most frequent adverse event was arterial hypotension with an incidence of $4.6 \%(38 / 823)$, followed by $\mathrm{SaO}_{2}<95 \%$ events with an incidence of $0.12 \%(1 / 823)$. No patients presented events of $\mathrm{SaO}_{2}<90 \%$. The incidence of nausea/vomiting episodes was $0.6 \%$ (5/823). No patients required advanced airway management or ACLS during this period (Table $3)$.

Multivariate analysis revealed a statistically significant association between obesity $(\mathrm{BMI}>30)$ and the incidence of $\mathrm{SaO}_{2}<90 \%$ events (Table 4). This association depicted a strong dose-effect relationship; taking nonobese patients as a reference, the risk of those with BMI 30-35 (grade 1 obesity) was almost double, with an OR of 1,68 (CI 95\% 0.84 to 3.32), while patients with BMI 35-40 (grade 2, severe obesity) and BMI $\geq 40$ (grade 3, morbid obesity) were three times (OR 2.85, CI 95\% 1.09 to 7.46) and nine times (OR 10.22, CI 95\% 2.83 to 36.99) more likely to experience $\mathrm{SaO}_{2}<90 \%$ events, respectively.

For arterial hypotension events, multivariate analysis showed a statistically significant association between these events and both colonoscopic procedures and propofol doses (OR 3.08, 95\% CI 1.43-6.61; $P=0.004$ and OR $1.14,95 \%$ CI $1.00-1.29 ; P=0.046$, respectively) (Table 5). After adjustment for potential confounders, a linear regression analysis showed a non-significant trend towards a reduction of $0.53 \mathrm{mg} . \mathrm{kg}-(95 \% \mathrm{CI}-0.86-0.2)$ in total propofol doses by concomitant fentanyl administration.

\section{Discussion}

Few evidence-based studies have examined the safety outcomes of low-risk patients undergoing propofol TCI sedation for ambulatory GIEPs. Approximately 20,000 GIEPs are performed at our institution per year under sedation managed by anaesthetists, in accordance with 
Table 2 Procedure characteristics

\begin{tabular}{lllll}
\hline Characteristic & $\begin{array}{l}\text { EGD alone } \\
n=166\end{array}$ & $\begin{array}{l}\text { Colonoscopy alone } \\
n=398\end{array}$ & $\begin{array}{l}\text { EGD and colonoscopy } \\
n=259\end{array}$ & $\begin{array}{l}\text { Total } \\
n=823\end{array}$ \\
\hline $\begin{array}{l}\text { Duration of procedure } \\
\text { Global mean duration (minutes) }\end{array}$ & $17.41 \pm 10.25$ & $24.15 \pm 10.18$ & $31.39 \pm 10.51$ & $25.07 \pm 11.43$ \\
$\quad$ Post-procedure discharge time & $41.26 \pm 9.11$ & $42.84 \pm 10.73$ & $44.79 \pm 16.29$ & $43.14 \pm 12.54$ \\
Medications & & & & \\
Propofol (mg) & $229.31 \pm 118.99$ & $282.83 \pm 112.66$ & $343.73 \pm 124.73$ & $291 \pm 124.6$ \\
Propofol (mg kg-1) & $3.17 \pm 1.62$ & $3.82 \pm 1.55$ & $4.70 \pm 1.56$ & $3.97 \pm 1.66$ \\
Fentanyl & $146(87.95)$ & $329(82.66)$ & $240(92.66)$ & $715(86.88)$ \\
Fentanyl (mcg) & $54.11 \pm 13.14$ & $56.05 \pm 16.84$ & $56.14 \pm 22.08$ & $55.68 \pm 18.14$ \\
Fentanyl (mcg kg & & $0.77 \pm 0.25$ & $0.78 \pm 0.28$ & $0.77 \pm 0.25$ \\
\hline
\end{tabular}

Results are presented as number (proportion) and mean \pm SD

$E G D$ esophagogastroduodenoscopy

institutional regulations. A safe anaesthetic technique with rapid turnover and discharge times is essential for this high-volume practice to remain efficient.

The study of our population demographics revealed that most patients scheduled for elective procedures on an outpatient basis had a low-risk profile ( $85 \%$ had ASA physical status classification scores I-II). Invasive diagnostic and therapeutic procedures were excluded from the investigation. The largest proportion of interventions consisted of colonoscopies alone, followed by colonoscopies combined with EGD; hence, we can state that this study involved a low-risk population undergoing low-risk procedures.
Regarding the administration of hypnotic drugs, Leslie et al. reported a mean total propofol dose of $200 \mathrm{mg}$ in a study including more than 2000 patients undergoing GIEPs [9], which is lower than the mean total propofol dose administered in the current investigation (291.2 $\mathrm{mg}$ ). Although a smaller proportion of patients in the study by Leslie et al. received propofol in combination with opioids (fentanyl or alfentanyl), the weight-adjusted doses of fentanyl were similar in both studies ( 0.78 vs. $0.77 \mathrm{mcg} . \mathrm{kg}^{-}$). In addition, $37 \%$ of patients in the aforementioned study also received $2 \mathrm{mg}$ of midazolam during anaesthesia induction, which has been proven to

Table $\mathbf{3}$ Intra-operative and post-operative outcomes

\begin{tabular}{|c|c|c|c|c|}
\hline & $\begin{array}{l}\text { EGD } \\
\text { alone } \\
n=166\end{array}$ & $\begin{array}{l}\text { Colonoscopy } \\
\text { alone } \\
n=398\end{array}$ & $\begin{array}{l}\text { EGD and } \\
\text { colonoscopy } \\
n=259\end{array}$ & Total $\boldsymbol{n}=823(\%)[95 \% \mathrm{Cl}]$ \\
\hline \multicolumn{5}{|l|}{ Intra-operative Outcomes } \\
\hline Hypoxia (SaO2 <95\%) & $39(23.49)$ & $81(20.35)$ & $64(24.71)$ & $\begin{array}{l}184(22.36)[19.55 \text { to } \\
25.36]\end{array}$ \\
\hline Hypoxia (SaO2 < 90\%) & $15(9.04)$ & $25(6.28)$ & $17(6.56)$ & $57(6.92)[5.29$ to 8.88$]$ \\
\hline Hypotension (SBP < 90 mmHg) & $8(4.82)$ & $71(17.84)$ & $25(9.65)$ & $\begin{array}{l}104(12.64)[10.44 \text { to } \\
15.10]\end{array}$ \\
\hline Administration of vasoactive drugs & $19(11.45)$ & $93(23.37)$ & $46(17.76)$ & $\begin{array}{l}158(19.20)[16.56 \text { to } \\
22.06]\end{array}$ \\
\hline $\begin{array}{l}\text { Bradycardia ( } \mathrm{HR}<50 \text { beats per minute) or atropine } \\
\text { administration }\end{array}$ & $4(2.41)$ & $16(4.02)$ & $19(7.34)$ & $39(4.74)[3.39$ to 6.42$]$ \\
\hline Unplanned SGD insertion or tracheal intubation & $2(1.20)$ & $2(0.5)$ & 0 & $4(0.5)[0.13$ to 1.24$]$ \\
\hline Need for ACLS & 0 & 0 & 0 & $0(0)[0$ to 0.45$]$ \\
\hline \multicolumn{5}{|l|}{ Post-operative outcomes } \\
\hline Hypoxia (SaO2 <95\%) & 0 & $1(0.25)$ & 0 & $1(0.12)[0$ to 0.6$]$ \\
\hline Hypoxia (SaO2< $<0 \%)$ & 0 & 0 & 0 & $0(0)[0$ to 0.45$]$ \\
\hline Hypotension (SBP < $90 \mathrm{mmHg}$ ) & $8(4.82)$ & $24(6.04)$ & $6(2.32)$ & 38 (4.6) [3.29 to 6.28$]$ \\
\hline PONV & $2(1.20)$ & $2(0.5)$ & $1(0.39)$ & 5 (0.6) [0.20 to 1.41$]$ \\
\hline Unplanned post procedural hospitalisation & 0 & 0 & 0 & $0(0)[0$ to 0.45$]$ \\
\hline
\end{tabular}

Results are presented as number (proportion), $95 \% \mathrm{Cl}$

$E G D$ esophagogastroduodenoscopy, $\mathrm{Cl}$ confidence interval, $\mathrm{SaO}_{2}$ oxygen saturation, $S B P$ systolic blood pressure, $H R$ heart rate, $S G D$ supraglottic device insertion, ACLS advanced cardiac life support, PONV post-operative nausea and/or vomiting 
Table 4 Multivariable logistic regression analysis for the association between oxygen desaturation $(<90 \%)$ and potentially related factors

\begin{tabular}{llll}
\hline & OR & $95 \% \mathrm{Cl}$ & $\boldsymbol{P}$ \\
\hline Grade $\mathbf{1}$ obesity & 1.68 & 0.85 to 3.33 & 0.14 \\
Grade $\mathbf{2}$ obesity & 2.86 & 1.09 to 7.46 & 0.03 \\
Grade 3 obesity & 10.23 & 2.83 to 36.99 & $<\mathbf{0 . 0 0 1}$ \\
Age & 1 & 0.98 to 1.02 & 0.99 \\
ASA physical status II & 1.88 & 0.60 to 5.82 & 0.28 \\
ASA physical status III & 2.14 & 0.56 to 8.20 & 0.26 \\
EGD & 1.17 & 0.66 to 2.06 & 0.58 \\
Received Fentanyl & 0.91 & 0.40 to 2.07 & 0.80 \\
Propofol dose $\mathbf{~ m g ~} \mathbf{~ k g}^{-\mathbf{1}}$ & 1.02 & 0.85 to 1.22 & 0.86 \\
\hline
\end{tabular}

OR odds ratio, $\mathrm{Cl}$ confidence interval, ASA American Society of

Anesthesiologists, $E G D$ esophagogastroduodenoscopy

reduce propofol requirements $[15,16]$. Therefore, the lower administered doses of propofol in the study by Leslie et al. could probably be attributed to the addition of midazolam, and not opioids, to the anaesthetic regimen. Despite the fact that our patients received larger doses of propofol, this was not associated with an increased incidence of arterial hypotension events, which was reported to be up to $12 \%$ in both studies [9].

When comparing our results with those from a study conducted by Chang et al. [13], the administered propofol doses in our practice were higher, although dispensed using TCI in both investigations. Patients in the study by Chang et al. received propofol as well as $2-2.5 \mathrm{mg}$ midazolam and a mean alfentanil dose of $493 \mathrm{ng}$. Again, combination of propofol TCI with benzodiazepines may account for the reduction in propofol requirements.

The procedure duration recorded in the present study (median time $25.07 \pm 11 \mathrm{~min}$ ) was similar to that reported by Leslie et al. However, we found differences in discharge times from the PACU; our mean time to hospital discharge was $42 \mathrm{~min}, \mathrm{IQR}$ [37 to 48 ] compared

Table 5 Multivariable logistic regression analysis for the association between hypotension $(<90 \mathrm{mmHg}$ ) and potentially related factors

\begin{tabular}{llll}
\hline & OR & $95 \% \mathrm{Cl}$ & $\boldsymbol{P}$ \\
\hline Colonoscopy & 3.08 & 1.43 to 6.61 & 0.004 \\
Propofol dose $\mathbf{~} \mathbf{~ g ~ k g}^{-1}$ & 1.14 & 1.00 to 1.29 & 0.046 \\
Age & 0.99 & 0.97 to 1.01 & 0.24 \\
ASA physical status II & 1.85 & 0.95 to 3.59 & 0.07 \\
ASA physical status III & 1.18 & 0.46 to 3.02 & 0.73 \\
Hypertension & 0.77 & 0.46 to 1.27 & 0.305 \\
Received Fentanyl & 1.22 & 0.63 to 2.35 & 0.55 \\
\hline
\end{tabular}

$O R$ odds ratio, $\mathrm{Cl}$ confidence interval, $A S A$ American Society of Anesthesiologists with $60 \mathrm{~min}, \mathrm{IQR}$ [33 to 82] in the previous study. Although it is difficult to compare the results without knowledge of the discharge criteria used in other studies, extended stay in the PACU may be related to the use of benzodiazepines. These drugs appear to prolong recovery time at the expense of similar hypotension rates [17].

Arterial hypotension was one of the most frequently encountered adverse events, with an incidence of 12 , $64 \%$. The administration of vasoactive drugs $(19.6 \%)$ was more frequent than the occurrence of arterial hypotension, probably related to the fact that many anaesthesiologists selected to administer them preemptively to avoid hypotension events. Although these incidences may appear high, we did not encounter major cardiovascular complications and none of the patients included in our study required ACLS or died during the perioperative period.

Through multivariate analysis, colonoscopic procedures and higher propofol doses were found to be associated with a higher incidence of arterial hypotension events. As reported in the literature, bowel cleansing with sodium phosphate relates to significant orthostatic hypotension and increases in heart rate, probably due to intravascular volume contraction $[18,19]$. This scenario can lead to an increased propensity to arterial hypotension events when combined with administration of propofol for deep sedation.

With respect to respiratory adverse events, $\mathrm{SaO}_{2}<95 \%$ was the most frequently encountered event (22.3\%); this drop in pulse oximetry likely represents upper airway obstructions with no significant clinical impact. Events of $\mathrm{SaO}_{2}<90 \%$ were encountered less often with an incidence of $6.9 \%$. Only four $(0.5 \%)$ patients required unplanned orotracheal intubation, suggesting that most $\mathrm{SaO}_{2}<95$ and $<90 \%$ events were resolved by noninvasive manoeuvres to unclog the airway including chin lift, jaw thrust, or insertion of oral/nasal cannulas. Considering the fact that the present study involved elective gastrointestinal procedures in relatively low-risk patients, the rates of significant hypoxia ( $\mathrm{SpO} 2<90 \%$ events) of $6.92 \%$ and unplanned orotracheal intubation of $0.5 \%$ were non-trivial. The authors believe that certain quality improvements could be incorporated to clinical practice, such as electroencephalographic monitoring and capnography tracing, which may allow for further analyses concerning the appropriate anaesthetic depth, recommended TCI target concentrations, and oxygenation/respiratory adequacy.

Multivariate analysis revealed a significant association between $\mathrm{SaO}_{2}<90 \%$ events and obesity. Morbid obesity showed a 10.22 OR for these events, probably suggesting the need for alternate airway management and/or oxygen supplementation strategies under sedation for these patients. The use of a high-flow nasal cannula or 
continuous positive airway pressure via nasal mask (SuperN2va) have been proposed to reduce oxygen desaturation events for spontaneously breathing obese patients [20, 21].

Most of the limitations of this study are related to information bias due to its retrospective nature. Hemodynamic variables were automatically captured from multiparameter monitors and graphically displayed. Although vasoactive drug administration data were obtained from these anaesthetic charts, the exact administration time registered by anaesthetists may not have been accurate; hence, it is difficult to determine whether these interventions were therapeutic or pre-emptive. Moreover, even when the total propofol doses were accurately documented due to institutional regulations for drug control, the TCI models (Marsch vs Schnider) and target concentrations selected for each patient throughout the procedure were not recorded. We did not encounter major events during the course of the procedures or the immediate post-operative period, and all patients were discharged from the hospital on the day of the procedure. Therefore, it is difficult to evaluate whether intraprocedural hypotension events had any long-term, directly related, cardiovascular or neurovascular consequences. Regarding oxygen desaturation, the use of non-invasive manoeuvres destined to increase oxygen saturation in patients registering $\mathrm{SpO}_{2}$ values under $95 \%$ is not regularly recorded in the anaesthetic chart.

\section{Conclusions}

Patients undergoing GIEPs under propofol TCI sedation combined with fentanyl were not exempted from experiencing cardiovascular or respiratory unplanned events, specifically grade II and III obese patients who showed a significant dose-effect relationship with $\mathrm{SpO} 2<90 \%$ events. Nonetheless, it appears to be an effective sedative strategy for GIEPs with the benefits of acceptable rates of unplanned adverse events, short discharge times, and rapid patient turnover. Further prospective studies should be conducted to accurately assess patient comfort and quality of sedation for this type of procedure.

\section{Abbreviations}

ACLS: Advanced cardiac life support; ASA: American Society of Anesthesiologists; BMI: Body mass index;

EGD: Esophagogastroduodenoscopy; ESA: European Society of Anesthesiology; GIEP: Gastrointestinal endoscopic procedure; HR: Heart rate; OR: Operating room; PACU: Post anaesthetic care unit; PONV: Post-operative nausea and/or vomiting; SBP: Systolic blood pressure; SGD: Supraglottic device; TCl: Target-controlled infusion

\section{Acknowledgements}

Not applicable.

\section{Authors' contributions}

MGG conceived the original idea and collaborated on the design of the study. This author also analysed and interpreted the patient data and participated in writing the manuscript. DSN and MSF collaborated on the design of the study, were in charge of collecting the data, analysed and interpreted the patient data, and participated in writing the manuscript. GD and SS were in charge of collecting the data for the study and participated in writing the manuscript. CT was an active mentor throughout the study's development and substantively revised the final manuscript. ST helped with the study design and statistical analysis. All authors read and approved the final manuscript.

\section{Funding}

None.

\section{Availability of data and materials}

The datasets used and/or analysed during the current study available from the corresponding author on reasonable request.

\section{Ethics approval and consent to participate}

Ethical approval was provided by the Ethics Committee of the Hospital Italiano de Buenos Aires, Buenos Aires, Argentina (Chairperson: Dr. Augusto Pérez, Ethical Committee $N^{\circ}$ 3885) on September 24, 2018. The requirement for written informed consent was waived due to the retrospective nature of the study.

\section{Consent for publication}

Not applicable.

\section{Competing interests}

The authors declare that they have no competing interests.

\section{Author details}

${ }^{1}$ Department of Anesthesiology, Hospital Italiano de Buenos Aires, Ciudad Autónoma de Buenos Aires, Presidente Teniente General Juan Domingo Perón 4190, 1199 Buenos Aires, Argentina. ²Department of Research, Hospital Italiano de Buenos Aires, Ciudad Autónoma de Buenos Aires, Presidente Teniente General Juan Domingo Perón 4190, 1199 Buenos Aires, Argentina.

Received: 26 May 2020 Accepted: 22 July 2020

Published online: 10 August 2020

\section{References}

1. Goulson DT, Fragneto RY. Anesthesia for gastrointestinal endoscopic procedures. Anesthesiol Clin. 2009;27:71-85.

2. Cohen LB, Wecsler JS, Gaetano JN, Benson AA, Miller KM, Durkalski V, et al. Endoscopic sedation in the United States: results from a nationwide survey. Am J Gastroenterol. 2006;101:967-74.

3. Lin OS. Sedation for routine gastrointestinal endoscopic procedures: a review on efficacy, safety, efficiency, cost and satisfaction. Intest Res. 2017; 15:456-66.

4. Singh H, Poluha W, Cheung M, Choptain N, Baron Kl, Taback SP. Propofol for sedation during colonoscopy. Cochrane Database Syst Rev. 2008, Issue 4. Art. No.: CD006268.

5. Heuss LT, Inauen W. The dawning of a new sedative: propofol in gastrointestinal endoscopy. Digestion. 2004;69:20-6.

6. Sethi S, Wadhwa V, Thaker A, Chuttani R, Pleskow DK, Barnett SR, et al. Propofol versus traditional sedative agents for advanced endoscopic procedures: a meta-analysis. Dig Endosc. 2014;26:515-24.

7. Delgado AAA, de Moura DTH, Ribeiro IB, Bazarbashi AN, Dos Santos MEL, Bernardo WM, de Moura EGH. Propofol vs traditional sedatives for sedation in endoscopy: a systematic review and meta-analysis. World J Gastrointest Endosc. 2019:11:573-88.

8. Lin OS, Kozarek RA, Tombs D, La Selva D, Weigel W, Beecher R, et al. The first US clinical experience with computer-assisted propofol sedation: a retrospective observational comparative study on efficacy, safety, efficiency, and endoscopist and patient satisfaction. Anesth Analg. 2017;125:804-11.

9. Leslie K, Allen ML, Hessian EC, Peyton PJ, Kasza J, Courtney A, et al. Safety of sedation for gastrointestinal endoscopy in a group of university-affiliated hospitals: a prospective cohort study. Br J Anaesth. 2017;118:90-9.

10. Lin OS, La Selva D, Kozarek RA, Tombs D, Weigel W, Beecher R, et al. One year experience with computer-assisted propofol sedation for colonoscopy. World J Gastroenterol. 2017;23:2964-71. 
11. Yang XY, Zhou ZB, Yang L, Zhou X, Niu L, Feng X. Hemodynamic responses during induction: comparison of marsh and Schnider pharmacokinetic models. Int J Clin Pharmacol Ther. 2015;53:32-40.

12. White M, Kenny GN. Intravenous propofol anaesthesia using a computerised infusion system. Anaesthesia. 1990;45:204-9.

13. Chang YT, Tsai TC, Hsu H, Chen YM, Chi KP, Peng SY. Sedation for gastrointestinal endoscopy with the application of target-controlled infusion. Turk J Gastroenterol. 2015;26:417-22.

14. American Society of Anesthesiologists. Continuum of Depth of Sedation: Definition of General Anesthesia and Levels of Sedation/Analgesia. Committee of Origin: Quality Management and Departmental Administration, 2009. https:/www.asahq.org/standards-and-guidelines/ continuum-of-depth-of-sedation-definition-of-general-anesthesia-and-levelsof-sedationanalgesia Accessed 17 May 2020.

15. VanNatta ME, Rex DK. Propofol alone titrated to deep sedation versus propofol in combination with opioids and/or benzodiazepines and titrated to moderate sedation for colonoscopy. Am J Gastroenterol. 2006;101:220917.

16. Wang D, Wang S, Chen J, Xu Y, Chen C, Long A, et al. Propofol combined with traditional sedative agents versus propofol- alone sedation for gastrointestinal endoscopy: a meta-analysis. Scand J Gastroenterol. 2013;48: $101-10$.

17. Chan W-H, Chang S-L, Lin C-S, Chen M-J, Fan S-Z. Target-controlled infusion of propofol versus intermittent bolus of a sedative cocktail regimen in deep sedation for gastrointestinal endoscopy: comparison of cardiovascular and respiratory parameters. J Dig Dis. 2014;15:18-26.

18. Labuschagne GS, Morris RW. The effect of oral intake during the immediate pre-colonoscopy time period on volume depletion in patients who receive sodium picosulfate. Anaesth Intensive Care. 2017:45:485-9.

19. Barclay RL, Depew WT, Vanner SJ. Carbohydrate-electrolyte rehydration protects against intravascular volume contraction during colonic cleansing with orally administered sodium phosphate. Gastrointest Endosc. 2002;56: 633-8.

20. Riccio CA, Sarmiento S, Minhajuddin A, Nasir D, Fox AA. High-flow versus standard nasal cannula in morbidly obese patients during colonoscopy: a prospective, randomized clinical trial. J Clin Anesth. 2019;54:19-24.

21. Bai Y, Xu Z, Chandrashekar M, St Jacques PJ, Liang Y, Jiang Y, et al. Comparison of a simplified nasal continuous positive airways pressure device with nasal cannula in obese patients undergoing colonoscopy during deep sedation: a randomised clinical trial. Eur J Anaesthesiol. 2019; 36:633-40.

\section{Publisher's Note}

Springer Nature remains neutral with regard to jurisdictional claims in published maps and institutional affiliations.

Ready to submit your research? Choose BMC and benefit from:

- fast, convenient online submission

- thorough peer review by experienced researchers in your field

- rapid publication on acceptance

- support for research data, including large and complex data types

- gold Open Access which fosters wider collaboration and increased citations

- maximum visibility for your research: over $100 \mathrm{M}$ website views per year

At $\mathrm{BMC}$, research is always in progress.

Learn more biomedcentral.com/submissions 